\title{
MEMBERS OF THE COUNCIL
}

1934

A. B. Coble, President.

OfFICERS

J. W. Alexander

MARSton Morse

H. S. VANDiver

Vice-Presidents.

R. G. D. Richardson, Secretary.

M. H. INGRAHAM

J. R. KLINE

Associate Secretaries.

T. M. Putnam

G. W. Mullins, Treasurer.

R. C. ARchibald, Librarian.

D. R. Curtiss

E. R. HEDRICK

W. R. Longley

R. D. Carmichael

F. R. SHARPE

J. D. TAMARKIN

E. T. BELL

R. L. MOORE

Oswald Veblen

E. T. BELL

E. W. Chittenden

G. C. Evans

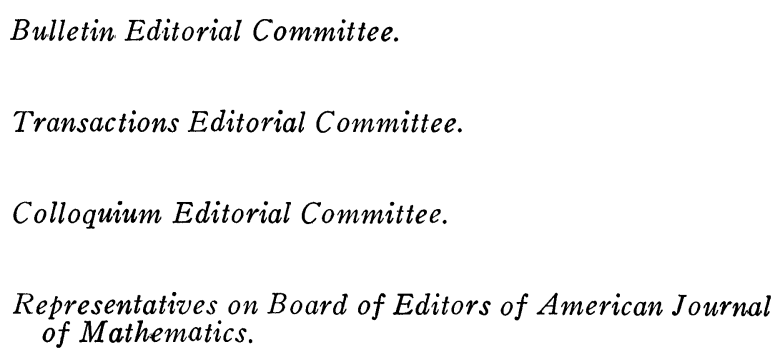

Transactions Editorial Committee.

Colloquium Editorial Committee.

Representatives on Board of Editors of American Journal of Mathematics.

\section{Ex-Presidents}

VIRGIL SNYDER,

E. R. HEDRICK,

L. P. Eisenhart.

Elected MEMbers

To serve until December, 1934

$\begin{array}{ll}\text { C. R. Adams, T. R. Hollcroft, } & \text { T. }\end{array}$

L. E. Dickson, C. C. MacDuffeE, W. E. Milne.

To serve until December, 1935

G. D. Birkhoff, L. M. Graves,

G. A. Bliss, Einar Hille,

G. Y. RaINICH.

To serve until December, 1936

J. R. CARSON, R. L. JEFFERY,

L. R. Ford, OYSTEIN ORE,

WARREN WEAVER.

\section{BOARD OF TRUSTEES}

1934

L. P. Eisenhart, Robert Henderson,

W. B. Fite, G. W. Mullins,

R. G. D. Richardson. 